\title{
A Decade of Advances in the Molecular Embryology and Genetics Underlying Congenital Heart Defects
}

\author{
Kazuki Kodo, MD, PhD; Hiroyuki Yamagishi, MD, PhD
}

\begin{abstract}
Congenital heart defects (CHD) are the most common type of human birth defect and result in significant mortality worldwide. Despite numerous epidemiologic studies in the past decades, few genetic causes have been identified until recently. CHD result from abnormal morphogenesis of the systematic cardiovascular construction during development. Recent advances in molecular embryology, including the discovery of a new source of cardiac progenitor cells termed the second heart field (SHF), have revealed that the heart arises from multiple distinct embryonic origins. Cells derived from the SHF contribute to the development of the cardiac outflow tract, together with the other progenitor cell lineage called cardiac neural crest cells. Numerous cardiac transcription factors regulate these progenitor cells during heart development. Elucidation of the transcriptional network for these cardiac progenitor cells is essential for further understanding cardiac development and providing new insights into the morphogenesis of $\mathrm{CHD}$. This review outlines the recent discoveries of the molecular embryology of the normal heart and the genetic basis of CHD. (Circ J 2011; 75: 2296-2304)
\end{abstract}

Key Words: Congenital heart disease; Genes; Genetics; Genotype; Pediatrics

$\mathbf{C}$ ongenital heart defects (CHD) occur in nearly $1 \%$ of all live births and are the major cause of infant mortality and morbidity. ${ }^{1}$ Additionally, approximately 3 per 1,000 live births will require some intervention during the first year of life. The multiple surgeries necessary to correct complex anatomical defects can be debilitating, and the quality of life of patients with CHD is often greatly compromised. Despite its clinical importance, the underlying genetic etiology of most CHD remains unknown, and they are so-called "multifactorial" diseases. The formation of the heart proceeds by sequential gene regulatory steps that dictate cell fates and organize specialized cell types into complex 3-dimensional units of structure and function. In order to explore the etiology of CHD, an approach focusing on the individual modular steps in cardiovascular morphogenesis is important, because most $\mathrm{CHD}$ result from abnormal morphogenesis in specific structural components of the developing heart and vessels. In this review, we discuss the recent 10-year advances in our understanding of the heart development within the framework of CHD.

\section{Developmental Origins of the Heart}

Decades of descriptive embryology, including cell lineage tracings, have improved our understanding of developmental origins of the heart (Figure 1). ${ }^{2,3}$ Cells derived from the anterior lateral plate mesoderm form a crescent shape at approximately embryonic (E) day 7.5 in the mouse embryo, corresponding roughly to week 2 of human gestation. By E8.0 in mice, or 3 weeks in humans, these cells coalesce along the ventral mid- line to form a primitive heart tube, consisting of an interior layer of endocardial cells and an exterior layer of myocardial cells, separated by extracellular matrix, called "cardiac jelly", for reciprocal signaling between the 2 layers. The crescentshaped pool of cardiogenic progenitor cells is now termed as the "first heart field" (FHF). ${ }^{2,3}$ The FHF that forms the heart tube, eventually contributes to specific chambers of the future heart, exclusively to the left ventricle and all other parts of the heart, except the cardiac outflow tract (OFT).

In addition to the FHF, it was reported 10 years ago that there was a second source of myocardial cells. ${ }^{4}$ In the mouse embryo, this source lies medially to the cardiac crescent and then behind the forming heart tube, extending into the mesodermal layer of the pharyngeal arches. This second source is termed the "second heart field" (SHF). ${ }^{2,3}$ The heart tube derived from the FHF may predominantly provide a scaffold upon which cells from the SHF migrate into both the arterial and venous poles of the heart tube, where they subsequently construct the requisite cardiac components. The contribution of the SHF to both the myocardium and smooth muscle of the arterial pole has been well studied (Figure 1). When the heart tube forms, SHF cells migrate into the midline and position themselves dorsal to the heart tube in the pharyngeal mesoderm. Upon rightward looping of the heart tube, SHF cells cross the pharyngeal mesoderm into the anterior and posterior portions, populating a large portion of the OFT, the future right ventricle, and the atria. The addition of SHF-derived myocardium to the OFT results in its elongation, which is necessary to allow the OFT to rotate sufficiently for the correct align-

Received June 15, 2011; revised manuscript received July 31, 2011; accepted August 8, 2011; released online September 14, 2011

Department of Pediatrics, Division of Pediatric Cardiology, Keio University School of Medicine, Tokyo, Japan

Mailing address: Hiroyuki Yamagishi, MD, PhD, Department of Pediatrics, Division of Pediatric Cardiology, Keio University School of

Medicine, 35 Shinanomachi, Shinjuku-ku, Tokyo 160-8582, Japan. E-mail: hyamag@ @s.itc.keio.ac.jp

ISSN-1346-9843 doi:10.1253/circj.CJ-11-0636

All rights are reserved to the Japanese Circulation Society. For permissions, please e-mail: cj@j-circ.or.jp 


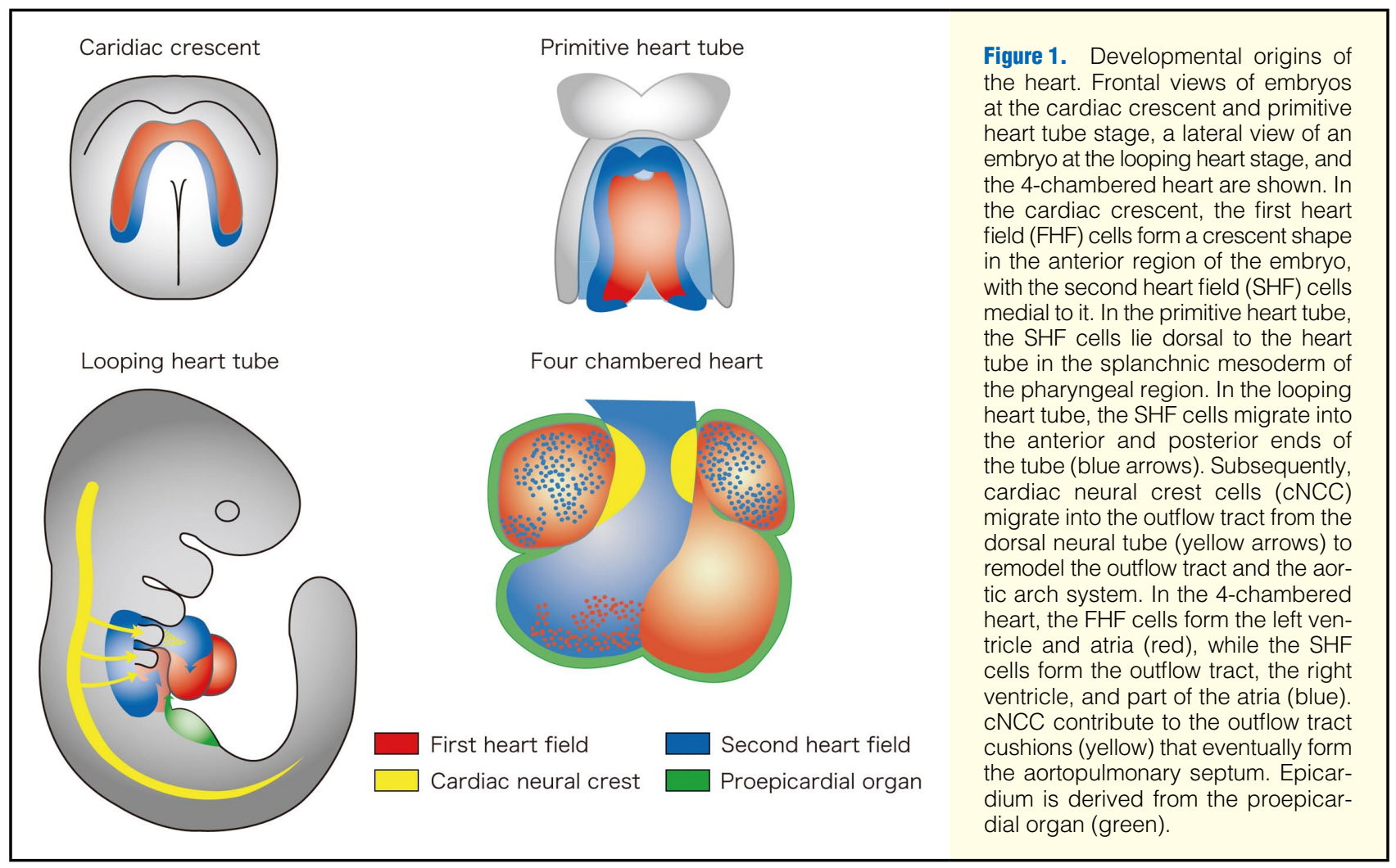

ment of the pulmonary and aortic trunks with their respective ventricles.

Cardiac neural crest cells (cNCC) originate from the dorsal neural tube between the mid-otic placode and the caudal boundary of the third somite..$^{5}$ After they delaminate from the dorsal neural tube, cNCC migrate into the caudal pharyngeal arches, and the OFT where they form the septum (Figure 1). Migration of the $\mathrm{cNCC}$ is also targeted to pharyngeal arches 3, 4 and 6, which give rise to the future great vessels (Figure 2). Many signaling pathways are involved in the migration and the condensation of $\mathrm{cNCC}$, including reciprocal signaling between cNCC and the SHF that are essential for the development of the OFT and the aortic arch system. ${ }^{6}$

The fourth lineage of cardiac precursor cells is derived from the proepicardium (PE). ${ }^{7}$ The PE develops from the coelomic mesothelium that overlays the liver bud, and the expression of PE-specific genes is induced in naïve mesothelial cells in response to a localized liver-derived signal. Almost all of the cells of the epicardium and the coronary vessels arise from the $\mathrm{PE}$, which develops as multiple epithelial villi protruding from the pericardial mesothelium immediately posterior to the sinoatrium of the looping stage embryonic heart. The PE extends towards the primitive heart, attaches, and spreads over the myocardial surface, forming the epicardium (Figure 1). During $\mathrm{PE}$ growth and epicardial formation, some PE/epicardial cells undergo an epithelial-mesenchymal transformation and are moved into the subepicardial space, giving rise to the precursors of the coronary vessels and connective tissue cells. ${ }^{8}$

\section{Transcription Factors Essential for the Heart Development}

The molecular mechanisms underlying heart development involving CHD have been elucidated in a decade by numerous investigations of cardiac specific transcription factors. ${ }^{9}$ After the signal stimulations for cardiac induction, such as Wnt and $\mathrm{BMP}$, heart development is governed by transcription factors that are evolutionally conserved and cross-regulate each other to control cardiac cell fates, the expression of genes encoding contractile proteins, and the morphogenesis of cardiac structures. The homeobox gene, $N k x 2.5$, also known as $C s x$, a homolog of Drosophila tinman, is expressed in cardiac progenitor cells, and serves as a target of inductive signals that initiate cardiogenesis. In mice lacking $N k x 2.5$, the initial events of heart formation occur normally, but embryos die from abnormal morphogenesis of the heart tube and failure of left ventricular development, which can be interpreted as a selective loss of derivatives of the FHF.

The $M e f 2$ gene is required for the differentiation of all types of muscles. Of the 4 vertebrate Mef 2 genes (Mef $2 a,-b,-c$ and $-d)$, Mef $2 c$ is required for activation of a subset of cardiac contractile protein genes, as well as for the development of cardiac structures derived from the SHF. ${ }^{10}$

Members of the GATA family of zinc finger transcription factors directly regulate numerous cardiac contractile protein genes as well as upstream regulatory genes such as $N k x 2.5$, Mef 2, and Hand. ${ }^{11}$ Of the 6 GATA genes in vertebrates, three (Gata4, -5 and -6 ) are expressed in the heart and have been implicated in heart development through loss-of-function mutations. Forced expression of cardiac GATA factors in Xenopus and zebrafish embryos induces premature activation of cardiac gene expression. ${ }^{12}$ Mutation of the GATA gene, pannier, in Drosophila results in an absence of cardioblasts and a decrease in the number of pericardial cells. ${ }^{11}$

Multiple T-box (Tbx) genes function to control cardiac fate, differentiation, and patterning of the dorsal vessel. ${ }^{13}$ At least 7 Tbx genes display overlapping expression in the FHF, SHF and other cardiac progenitors of amniotes. Mice lacking $T b x 5$ 


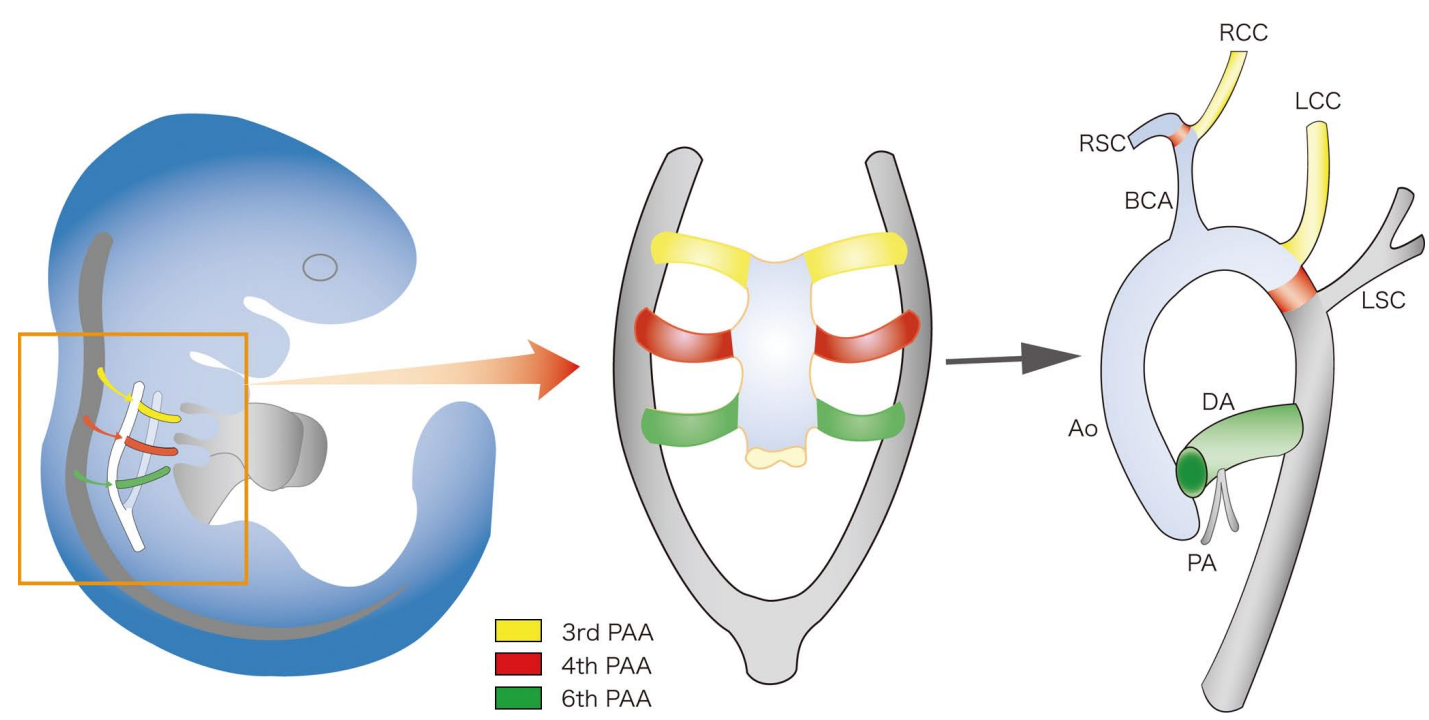

Figure 2. Cardiac neural crest cells contributing to the aortic arch development. A lateral view of an embryo ( $\approx$ day 30 in humans or embryonic day 10.5 in mice) and a frontal view of the bilateral pharyngeal arch arteries (PAA). Migration of the cardiac neural crest cells is targeted to the $3^{\text {rd }}, 4^{\text {th }}$ and $6^{\text {th }}$ PAA that give rise to the aortic arch system as shown to the right. The right and left $3^{\text {rd }}$ PAA give rise to the right (RCC) and left (LCC) common carotid artery, respectively. The right $4^{\text {th }}$ PAA contributes to forming a segment that connects the right subclavian artery (RSC) to the brachiocephalic artery (BCA). The left $4^{\text {th }}$ PAA forms the transverse segment of the aorta (Ao). The right $6^{\text {th }}$ PAA is not maintained whereas the left $6^{\text {th }}$ PAA contributes to the ductus arteriosus (DA). PA, pulmonary arteries.

display defects in the posterior region of the heart tube, which gives rise to the atria. ${ }^{14}$ Tbx 5 and Tbx 20 have also been implicated in the formation of the cardiac conduction system and ventricular chambers. ${ }^{15}$ Tbx 2 and Tbx 3 function as repressors of chamber myocardium and are associated with the development of the conduction system. ${ }^{16}$

The Drosophila genome encodes a single member of the Hand family of bHLH transcription factors that is required for normal development of the dorsal vessel. ${ }^{17}$ The correlation between gene duplication and cardiac complexity is especially intriguing with respect to the Hand genes, which regulate ventricular growth. Although in zebrafish there is only 1 Hand gene that is essential for the development of the single ventricle of this organism, ${ }^{18}$ there are 2 Hand genes (Handl and 2) in mice. ${ }^{19}$ Handl and Hand 2 are preferentially expressed in derivatives of the FHF and SHF, respectively. Mice lacking Hand2 do not form a right ventricle, whereas Handl mutant embryonic stem cells are unable to contribute to the outer curvature of the heart that gives rise to the left ventricle. ${ }^{20}$ Evolutionary duplication of the ventricular chambers, thus, correlates with duplication of the Hand genes.

\section{Molecular Regulation of the SHF}

Since the discovery of the SHF in 2001, molecular pathways regulating the SHF have been extensively investigated (Figure 3). The SHF is marked by the LIM-homeodomain transcription factor, Islet1 (Isl1), and comprises the dorsalmedial aspect of the cardiogenic plate, whereas the FHF comprises the ventral aspect of the cardiogenic plate (Figure 1). ${ }^{21}$ Expression of Isl1 is extinguished as progenitor cells express markers of cardiac differentiation, although Isl1 is necessary for the SHF-derived cells to populate the heart. After the heart tube has formed, canonical Wnt signaling is maintained in the SHF. ${ }^{22} \beta$-catenin is required in the Isl1-expressing SHF progenitors. Genetic ablation of $\beta$-catenin results in pharyngeal arch remodeling defects, a single outflow vessel, and embryonic lethality, indicating disruption of the myocardial contribution from the SHF. Loss of Wnt signaling reduces the number of Isl1-positive cells, leading to OFT and right ventricular defects, whereas excess Wnt signaling expands the Isl1-positive population. ${ }^{23}$ Canonical Wnt signaling is responsible for promoting proliferation and maintaining cells in a progenitor state. Meanwhile, $\beta$-catenin induces both BMP4 and noncanonical Wnt11 expression in the SHF, suggesting that the early canonical Wnt signaling also sets the stage for differentiation. Non-canonical Wnt signaling, on the other hand, promotes cardiac differentiation and is specifically required for the OFT development. ${ }^{24}$

Hand 2 is a good candidate for controlling the development of the SHF because it is expressed predominantly in the right ventricle and the OFT. Hand2-null mice show severe hypoplasia of the right ventricle and growth retardation from E9.5, with death by E10.5. ${ }^{20}$ However, the early embryonic lethality of Hand2-null mice has precluded lineage-specific study of its function in myocardial progenitors. Recently, we used a floxed allele of Hand 2 to ablate its expression in specific cardiac cell populations at defined developmental points. We found that Hand 2 expression within the mesoderm-derived SHF progenitors was required for their survival and deletion in this domain recapitulated the complete Hand2-null phenotype..$^{25}$

Similarly, right ventricular hypoplasia in mice lacking $M e f 2 c$ may also be a defect of the SHF. Mef2c is a target of Isl1, Gata4, Foxh1, and Tbx20 during the development of the SHF. ${ }^{26,27}$ As a matter of fact, many of transcriptional regulators of the FHF, including Nkx2.5 and Gata4, are expressed in a population of cardiogenic progenitor cells derived from the SHF and may target its development. 


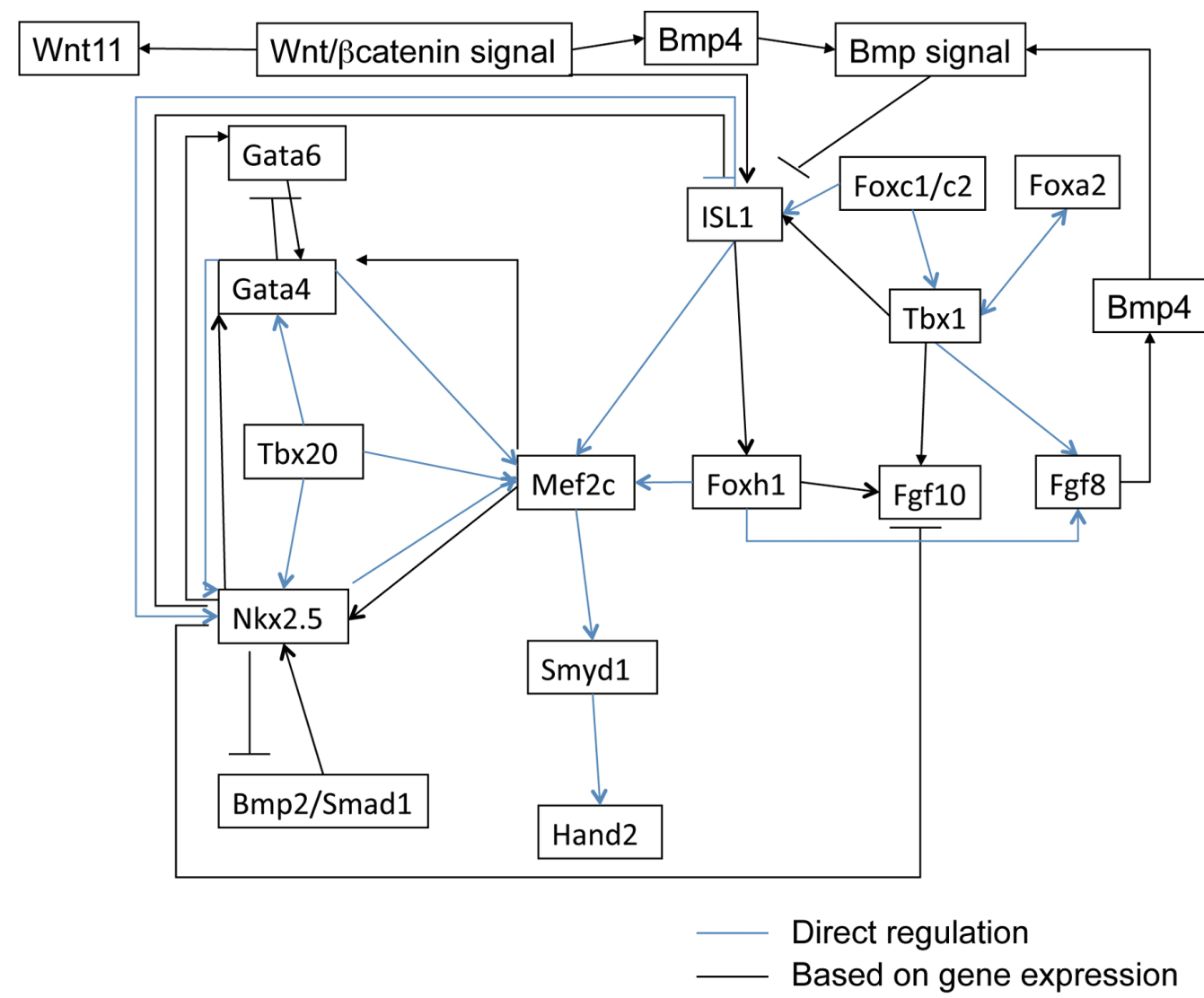

Figure 3. Molecular pathways controlling the second heart field. Direct in vivo regulations are indicated by blue lines, and genetic expression data are indicated by black lines. See text for detail.

The significance of transcriptional regulation in the SHF is highlighted by the CHD in 22q11.2 deletion syndrome (22q11DS), the most common chromosome microdeletion syndrome in humans. ${ }^{28,29} \mathrm{~A}$ T-box transcription factor, TBX1, on the 22q11.2 region is a major genetic determinant of cardiac and craniofacial disorders. Tbx 1 is expressed in the SHF, but not in the FHF or cNCC. ${ }^{30}$ OFT defects, such as persistent truncus arteriosus (PTA) and tetralogy of Fallot (TOF), and aortic arch anomalies are highly associated with 22q11DS, as well as craniofacial defects, such as cleft palate. Tbxl-null mice phenocopy the 22q11DS phenotype. Tissue-specific disruption of Tbxl in the expression domain of $N k x 2.5$ developed the single OFT with no evidence of an aortopulmonary septum, suggesting that loss of Tbx1 function in the SHF or pharyngeal endoderm may result in OFT defects. ${ }^{31}$ Shh plays a role in maintenance of the expression of Tbx $1 . .^{30,32}$ The expression of Tbx1 in the SHF is directly regulated by forkhead-containing (Fox) transcription factors, Foxa2, Foxc1 and Foxc2, through at least 2 enhancer regions including the consensus Fox binding sites. ${ }^{32,33}$ The Tbxl-hypomorphic mouse demonstrated that the development of the OFT was more sensitive to Tbx 1 dosage than craniofacial development. The increased dose-dependency in the OFT is likely related to amplification of Tbx1 via an autoregulatory loop involving Foxa2 and Tbx1 in the SHF, resulting in upregulation of the downstream targets, Fgf 8 and $10 .{ }^{34}$ In experiments using knockout mice, Foxc1 and Foxc2, and Foxh1 were involved in the development of the OFT, although Foxa2-null mice die too early in utero to study cardiac development. Foxc1- or Foxc2-null mice and compound heterozygous mice for Foxcl and Foxc2 display aortic arch defects reminiscent of $T b x 1$ heterozygous mice. ${ }^{35}$ Interestingly, they also display a reduction in the size of the OFT and right ventricle, suggesting a dose-dependent regulatory mechanism of Foxc1 and Foxc2 in the SHF. ${ }^{36}$ Moreover, embryos homozygous-null for both Foxcl and Foxc2 display an absence of the OFT and right ventricle, as well as downregulation of Tbx1, Fgf8, and Fgf10.

In contrast, there is no evidence of genetic interaction between Foxh1 and Tbx1, although Foxh1 plays an important role in the SHF development. Consistent with this observation, the consensus binding sequence for Foxh1 is different from those for Foxa2, Foxc1, and Foxc2. A recent study demonstrated that Foxh1 was able to form a transcriptional complex with Nkx2.5 and to regulate Mef2c expression in the SHF and OFT, and that Foxh1-null mice have OFT defects. ${ }^{27}$ A Foxa2/ $\mathrm{c} 1 / \mathrm{c} 2-\mathrm{Tbx} 1$ pathway, therefore, may be parallel to or independent of the Foxh1/Nkx2.5-Mef2c pathway in terms of regulating the SHF (Figure 3).

Intracellular calcium signaling is known to play essential roles in cardiac physiology and hypertrophy, but its function in cardiac development remains to be elucidated. Inositol 1, 4,5-trisphosphate receptor $\left(\mathrm{IP}_{3} \mathrm{R}\right)$ is an intracellular calcium release channel on the endo/sarcoplasmic reticulum. Three subtypes of $\operatorname{IP}_{3} \mathrm{R}(1,2$, and 3 ) have been identified in many organs 


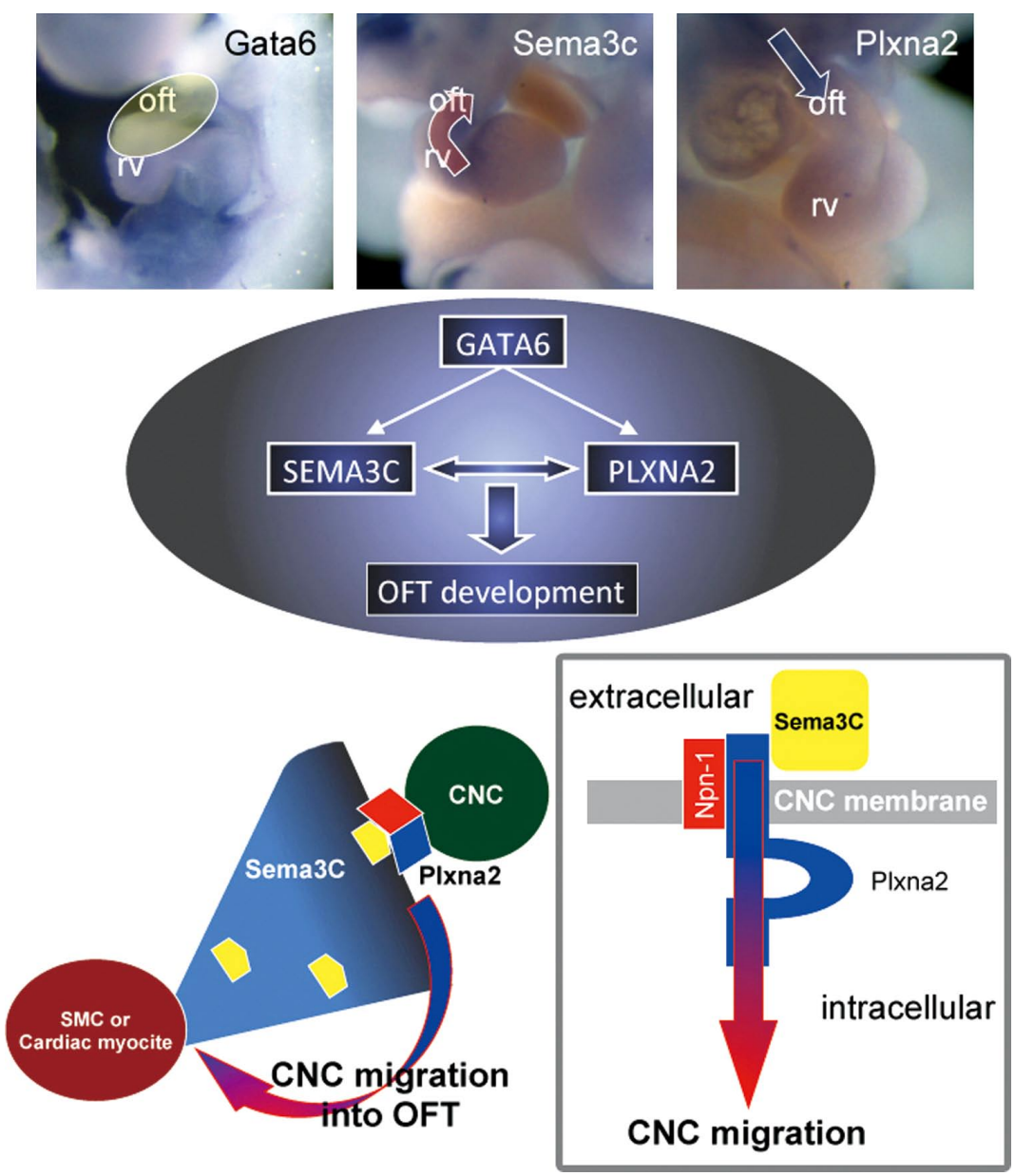

Figure 4. Final step in the migration of cardiac neural crest (CNC) into the outflow tract (OFT), orchestrated by GATA6SEMA3C-PLXNA2 signaling. The expression of Gata6 (Top left), Sema3c (Top center) and Plxna2 (Top right) by RNA in situ hybridization are shown in the OFT of mouse embryos around E10.5. Gata6 is strongly expressed in the OFT (yellow oval), Sema3c is in the right ventricle (rv) and the OFT (red arrow), and Plxna2 is in CNC migrating into the OFT (blue arrow). A current model is shown in the central oval: GATA6 directly regulates SENA3CPLXNA2 signaling for CNC migration during the development of the OFT. Sema3c (colored in yellow) is secreted from smooth muscle cells (SMC) or cardiomyocytes of the OFT, binds to its receptor complex, Plxna2-neuropilin1 (Npn-1) on the surface of CNC and may transmit a migration signal for CNC into the OFT as shown in the lower diagrams.

during embryogenesis and the postnatal period. ${ }^{37}$ Recently, we reported a redundant role of $\mathrm{IP}_{3} \mathrm{R} 1$ and $\mathrm{IP}_{3} \mathrm{R} 2$ during cardiogenesis, implicating the calcineurin/NFAT signaling pathway in the development of the endocardial cushion..$^{38}$ Furthermore, we showed that $I_{3} R 1$ and $I_{3} R 3$ are redundantly essential for the development of the SHF. ${ }^{39}$ Although the molecular mechanisms underlying $\mathrm{IP}_{3} \mathrm{R}$-mediated $\mathrm{Ca}^{2+}$ signaling in the $\mathrm{SHF}$ are not fully understood, our study demonstrated that redundant roles of $\mathrm{IP}_{3} \mathrm{R} 1$ and 3 might be implicated in the regulation of cell survival and the Mef2c-Smyd1 transcriptional cascade during the development of the SHF.

\section{Molecular Regulation of cNCC}

The specification and induction of cNCC involves a number of secreted signals, including Wnt, BMP, FGF and retinoic acid, that are critical for the induction of the neural plate border. ${ }^{40}$ Importantly, the canonical Wnt $\beta$-catenin pathway is specifically required for cNCC induction. ${ }^{41}$ The combined action of these secreted signals triggers the expression of neural crest specifier genes, such as transcription factors, Snail2, Sox 9 and FoxD3. ${ }^{42}$

The cNCC have definitive migration patterns and stereotypic destinations. ${ }^{43}$ Throughout their journey, cNCC interact with a multitude of signaling factors, many of which may help guide them and reciprocally, the cNCC may pattern and contribute to many of the structures in proximity to these secreted factors. The role for FGF signaling in migrating cNCC development remains somewhat elusive. FGF8-hypomorphic mice show apoptosis of $\mathrm{cNCC}$ as they emigrate from the neural tube and in the pharyngeal arches. ${ }^{44} F G F 2$ expression is promoted by FGF8 and is a prerequisite for the differential localization of FGF2, which is essential for chemotaxis of mesencephalic NCC migration. ${ }^{45}$ Decades of ablation studies have revealed much of what is known about the roles of cNCC..$^{5,46}$

The final migration of cNCC into the OFT is guided by Semaphorin 3C (SEMA3C). The myocardium underlying the pulmonary side of the undivided OFT expresses SEMA3C while cNCC express its receptor, Plexin A2 (PLXNA2), and are attracted by the SEMA3C ligand. ${ }^{47}$ Semaphorins are secreted, transmembrane and GPI-linked proteins that were initially found to be important in axonal guidance in the developing nervous system. ${ }^{48}$ Semaphorin ligands bind to plexin and neuropilin receptors, which lead to alterations in the cytoskeleton and microtubule network. This signaling is required for the correct migratory patterning of cNCC into the OFT (Figure 4). In $75 \%$ of newborn Sema3c mutant mice, there is incomplete septation of the OFT and these animals have a single semilunar valve with 4 cusps and a ventricular septal defect just below the valve. ${ }^{49,50}$ Interestingly, the PLXNA2 receptor is expressed in not only migrating, but also postmigratory cNCC, suggesting that the final step of migration of cNCC into the OFT may be orchestrated by SEMA3C-PLXNA2 signaling.

The transforming growth factor $\beta$ (TGF $\beta$ ) superfamily, 


\begin{tabular}{|c|c|c|}
\hline Gene & CHD & References \\
\hline NKX2.5 & $\begin{array}{l}\text { TOF, ASD, DORV, VSD, HLHS, CoA, IAA, } \\
\text { TGA, Ebstein }\end{array}$ & $\begin{array}{l}\text { Schott JJ et al; Hirayama-Yamada K et al; Gutierrez-Roelens I et al; Hosoda T et al; } \\
\text { Watanabe Y et al; Gutierrez-Roelens I et al; Elliott DA et al; Rifai L et al; Benson DW } \\
\text { et al; Goldmuntz E et al; McElhinney DB et al; De Luca A et al; Akcaboy MI et al; } \\
\text { Konig K et al; Ikeda Y et al; Bjornstad PG et al; Pabst S et al; Gioli-Pereira L et al; } \\
\text { Akcaboy MI et al; Rauch R et al }\end{array}$ \\
\hline GATA4 & ASD, AVSD, VSD, TOF, HRHS, PAPVC & $\begin{array}{l}\text { Garg V et al; Hirayama-Yamada K et al; Okubo A et al; Sarkozy A et al; Tomita- } \\
\text { Mitchell A et al; Zhang W et al; Rajagopal SK et al; Nemer G et al; Schluterman MK } \\
\text { et al; Posch MG et al }\end{array}$ \\
\hline ZIC3 & TGA, ASD, PS & Chhin B et al; Megarbane A et al; Ware SM et al; De Luca A; Gebbia M et al \\
\hline FOG2 & TOF, DORV & Pizzuti A et al; De Luca A et al \\
\hline FOXH1 & TGA, TOF & Roessler E et al \\
\hline GATA6 & PTA, PS, AVSD & Kodo K et al; Lin X et al; Maitra $\mathrm{M}$ et al \\
\hline NKX2.6 & PTA & Heathcote $\mathrm{K}$ et al \\
\hline TBX20 & ASD, CoA, VSD, PDA, MS, HLHS & Kirk EP et al; Posch MG et al \\
\hline CITED2 & VSD, ASD & Sperling S et al \\
\hline TBX5 & ASD, VSD, AVSD & Basson CT et al. *Associated with Holt-Oram syndrome. \\
\hline TBX1 & VSD, IAA, PAVSD & $\begin{array}{l}\text { Yagi } \mathrm{H} \text { et al; Rauch } \mathrm{R} \text { et al; Gong } \mathrm{W} \text { et al; Rauch } \mathrm{A} \text { et al. "Associated with } \\
\text { DiGeorge/Conotruncal anomaly face syndrome. }\end{array}$ \\
\hline ANKRD1 & TAPVC & Cinquetti $R$ et al \\
\hline HAND1 & TOF, Atrial isomerism & Hatemi AC et al; Wang $\mathrm{J}$ et al \\
\hline HAND2 & TOF & Shen $L$ et al \\
\hline
\end{tabular}

CHD, congenital heart defects; TOF, tetralogy of Fallot; ASD, atrial septal defect; DORV, double outlet right ventricle; VSD, ventricular septal defect; HLHS, hypoplastic left heart syndrome; CoA, coarctation of aorta; IAA, interrupted aortic arch; TGA, transposition of great arteries; AVSD, atrioventricular septal defect; HRHS, hypoplastic right heart syndrome; PAPVC, partial anomalous pulmonary venous connection; PS, pulmonary valve stenosis; PTA, persistent truncus arteriosus; PDA, patent ductus arteriosus; MS, mitral valve stenosis; PAVSD, pulmonary atresia with ventricular septal defect; TAPVC, total anomalous pulmonary venous connection.
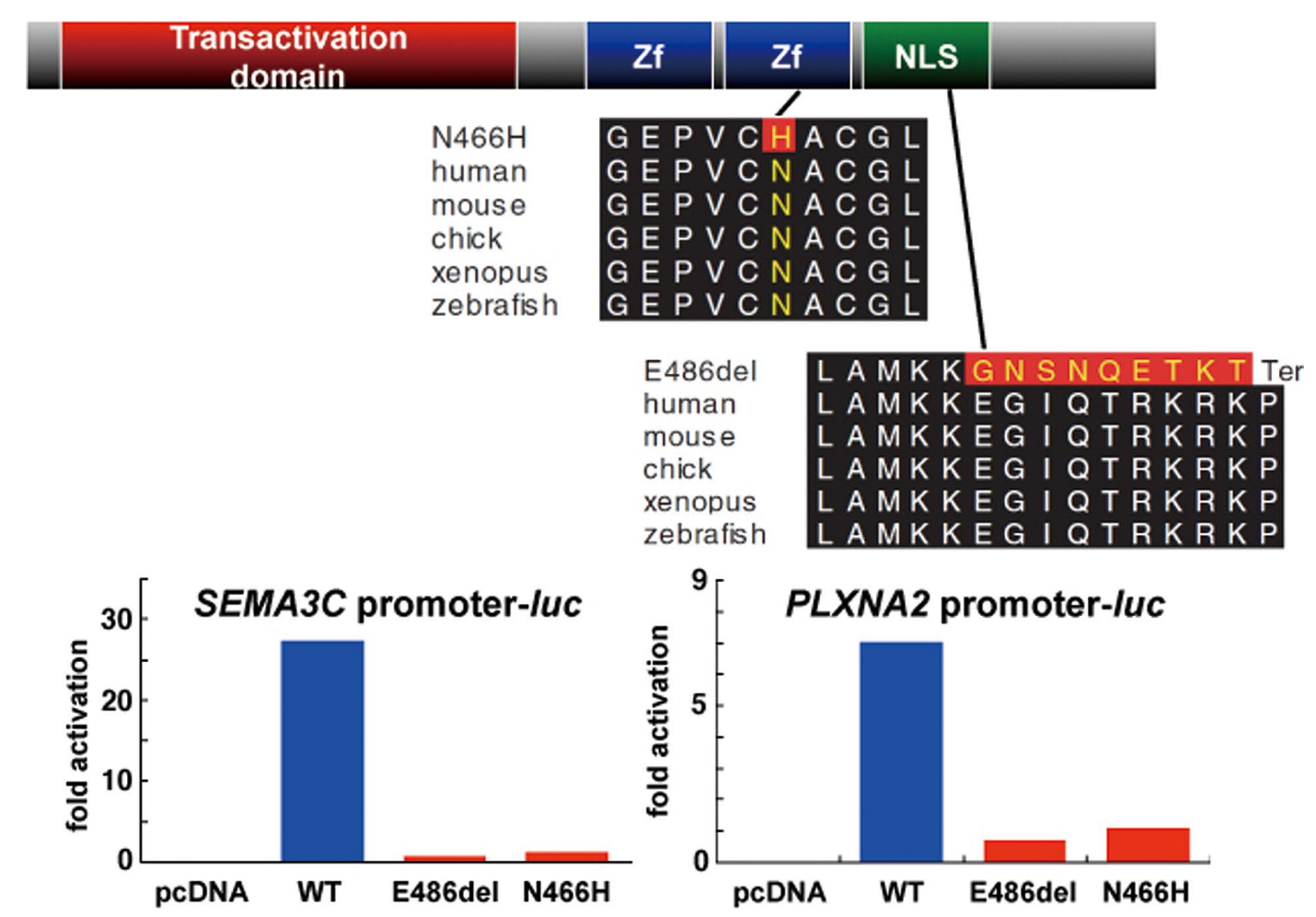

Figure 5. Novel mutations in GATA6 associated with persistent truncus arteriosus result in failure of transactivation of downstream target genes, SEMA3C and PLXNA2. (Top) The construction of GATA6 with positions of novel mutations (N466H and E486del) and conservation of alignment between species is shown. GATA6 mutant proteins show a significant decrease in transcriptional activity on SEMA3C (Lower left) and PLXNA2 (Lower right) promoters compared with the wild-type (WT). Zf, zinc finger domain; NLS, nuclear localization signal; Ter, terminal codon; luc, luciferase reporter. 


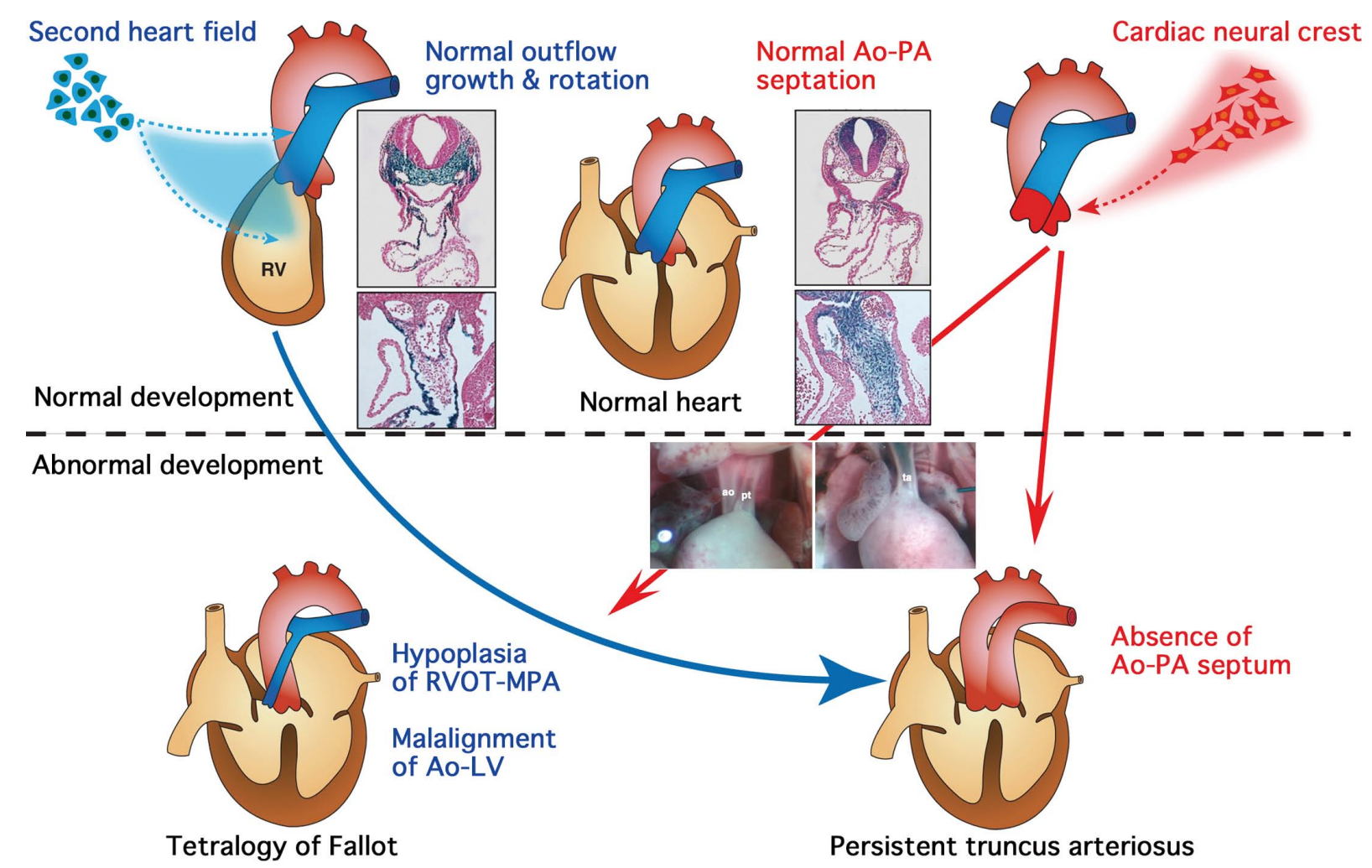

Figure 6. Contribution of second heart field (SHF)-derived cells and cardiac neural crest-derived cells to the outflow tract development and defects. Blue cells in the upper insets represent SHF-derived cells on the left and cardiac neural crest-derived cells on the right, respectively. Lower insets show the normal outflow tract divided into the aorta (ao) and pulmonary trunk (pt) on the left, and failure to form the Ao-PA septum leading to persistent truncus arteriosus (ta) on the right.

including BMP and TGF $\beta$ ligands, is one of the most widely studied signaling families that affect $\mathrm{cNCC}$ development. ${ }^{51}$ The TGF $\beta$ subfamily ligands signal via a receptor complex composed of 2 type II receptors and 2 type I receptors. Upon ligand binding, type II receptors, which are constitutively active kinases, phosphorylate and activate type I receptors (ALKs). Type I receptors phosphorylate and activate a specific set of downstream signaling molecules called Smads. In general terms, TGF $\beta$ s bind to the TGF $\beta$ type II receptor (TGF $\beta$ RII) and TGF $\beta$ type I receptor (ALK5) activating $\operatorname{Smad} 2$ and 3, while BMPs bind to the BMP type II receptor and type I receptors ALK2, 3, or 6, activating Smad1, 5 and 8.52 Alk2 is required either for normal migration and/or maintenance of cNCC in the pharyngeal arches and OFT. ${ }^{53}$ Canonical TGF $\beta$ or BMP signaling results in phosphorylation of different Smads, but these phosphorylated Smads all bind the universally used co-Smad4. ${ }^{54}$ The Smad4 complex is then translocated to the nucleus where it alters transcription. Conditional deletion of Smad4 in cNCC using Wnt1-cre leads to failure of the OFT septation. ${ }^{55}$

\section{Molecular Genetics of CHD}

The association between mutations in NKX2.5 and atrial septal defect (ASD) with atrioventricular block was first published in 1998. ${ }^{56}$ Since then, some cardiac transcription factor genes have been demonstrated in a decade to be associated with various CHD (Table).
Recently, we screened mutations of cardiac transcription factors in patients with selected non-syndromic CHD, namely PTA, representing the most severe cardiac OFT defect, and identified 2 different GATA6 mutations in 2 probands, but not in 182 unrelated controls with no CHD. ${ }^{57}$ Our subsequent biological analyses revealed that SEMA3C and PLXNA2 were directly regulated by GATA6, and that both GATA6 mutant proteins failed to transactivate these genes (Figure 5). Transgenic analysis further suggested that the expression of SEMA3C and PLXNA2 in the OFT was dependent on GATA transcription factors during heart development. Together, our data implicate mutations in GATA6 as novel genetic causes of CHD involving the OFT, as a result of disruption of the direct regulation of semaphorin-plexin signaling (Figure 4).

After our study, there have been 2 reports on mutations in GATA6 associated with CHD. Maitra et al showed 2 novel sequence variations in GATA6 (A178V and L198V) from the screening of 310 individuals with non-syndromic CHD. ${ }^{58}$ These variants were identified in 2 individuals, 1 with TOF and the other with atrioventricular septal defect, but not in 288 ethnically-matched healthy controls. Biochemical analysis demonstrated that the GATA6 A178V mutant protein resulted in increased transactivation ability for cardiac genes compared with the wild-type. Lin et al screened 270 individuals with non-syndromic CHD and identified a missense mutation (S184N) of GATA6 in 2 individuals, 1 with TOF and the others with ASD. ${ }^{59}$ Although incomplete penetrance of the phenotype by this mutation was observed, the mutation was 
not found in 500 ethnically-matched healthy controls. Their subsequent biological analysis revealed the decreased transcriptional activity of GATA6 with the S184N mutation for regulation of several important cardiac genes, suggesting that the GATA6 S184N mutation may play an important role in the pathogenesis of CHD.

To date, the implication of GATA6 and GATA4 in CHD, as well as their genetic interaction, has been suggested. Genetic disruption of Gata6 in mice results in early embryonic lethality from defects of endodermal differentiation. Conditional inactivation of Gata6 specifically in cNCC causes PTA, suggesting an essential role of Gata6 during OFT development. ${ }^{60}$ Homozygous Gata4 knockout mice die in utero and develop 2 symmetric promyocardial primordia that fail to migrate ventrally and form the heart tube. Mice with heterozygous Gata4 mutations exhibit septal defects and endocardial cushion defects. ${ }^{61}$ Mice that are compound heterozygous for Gata4 and Gata6 null alleles die in utero and exhibit a spectrum of CHD, including septal and OFT defects. ${ }^{62}$ It has also been shown that GATA6 and GATA4 regulate the expression of each other during development and that GATA6 may function in concert with GATA4 to direct tissue-specific gene expression essential for formation of the mammalian heart. It is of note that GATA6 mutations identified in humans are predominantly associated with OFT defects, whereas GATA4 mutations are commonly associated with septal defects, although there is some phenotypic overlap (Kodo K, Yamagishi H, unpublished data), probably resulting from a redundant role of these genes. Although the clinical phenotype of individuals with GATA6 mutations commonly involves the OFT, it is distinct from that of 22q11DS and, rather, manifests as non-syndromic CHD. To date, no molecular link has been demonstrated between GATA6 and TBX1; however, our recent study suggests that the expression of Sema3c in the OFT is altered in mouse embryos deficient for Tbxl (Kodo K, Yamagishi H, unpublished data), suggesting that GATA6 may share, at least in part, a common molecular pathway with TBX1 during OFT development.

\section{Concluding Remarks}

Through the use of animal models combined with human genetic investigations, a molecular framework that controls cardiovascular morphogenesis and a molecular basis of CHD have emerged in this decade (Figure 6).,2,363 Such advances in understanding lead to an approach to the etiology of "multifactorial" CHD in the post-genomic era, although the underlying genetic etiology of the majority of CHD that manifest as non-syndromic and non-familial phenotypes still remains to be elucidated. Environmental factors, epigenetic factors and/or other genetic modifiers may also be responsible for the final phenotype of CHD. Further studies are necessary for more delineated genotype-phenotype correlations between gene mutations and CHD phenotype, and the next challenge is identifying factors that modify or influence the phenotype. An improved understanding of possible genetic causes gives an insight into the pathogenesis, and, eventually, the regenerative medicine for CHD. Our next hope is to target prevention or genetic intervention of $\mathrm{CHD}$, utilizing such progress in basic science.

\section{Acknowledgments}

We thank Dr Chihiro Yamagishi for making the figures. This work is supported by a Grant-in-Aid for Scientific Research from the Ministry of Education, Culture, Sports, Science and Technology, Japan to H.Y., K.K. is supported by a Grant-in-Aid for Young Scientists from the Ministry of Education, Culture, Sports, Science and Technology, Japan.

\section{References}

1. Hoffman JI, Kaplan S. The incidence of congenital heart disease. J Am Coll Cardiol 2002; 39: 1890-1900.

2. Buckingham M, Meilhac S, Zaffran S. Building the mammalian heart from two sources of myocardial cells. Nat Rev Genet 2005; 6: 826835.

3. Srivastava D. Making or breaking the heart: From lineage determination to morphogenesis. Cell 2006; 126: 1037-1048.

4. Kelly RG, Brown NA, Buckingham ME. The arterial pole of the mouse heart forms from Fgf10-expressing cells in pharyngeal mesoderm. Dev Cell 2001; 1: 435-440.

5. Hutson MR, Kirby ML. Model systems for the study of heart development and disease: Cardiac neural crest and conotruncal malformations. Semin Cell Dev Biol 2007; 18: $101-110$.

6. Waldo KL, Hutson MR, Stadt HA, Zdanowicz M, Zdanowicz J, Kirby ML. Cardiac neural crest is necessary for normal addition of the myocardium to the arterial pole from the secondary heart field. Dev Biol 2005; 281: 66-77.

7. Mikawa T, Gourdie RG. Pericardial mesoderm generates a population of coronary smooth muscle cells migrating into the heart along with ingrowth of the epicardial organ. Dev Biol 1996; 174: 221-232.

8. Olivey HE, Svensson EC. Epicardial-myocardial signaling directing coronary vasculogenesis. Circ Res 2010; 106: 818-832.

9. Bruneau BG. Transcriptional regulation of vertebrate cardiac morphogenesis. Circ Res 2002; 90: 509-519.

10. Olson EN. Gene regulatory networks in the evolution and development of the heart. Science 2006; 313: $1922-1927$.

11. Sorrentino RP, Gajewski KM, Schulz RA. GATA factors in Drosophila heart and blood cell development. Semin Cell Dev Biol 2005; 16: $107-116$.

12. Latinkić BV, Kotecha S, Mohun TJ. Induction of cardiomyocytes by GATA4 in Xenopus ectodermal explants. Development 2003; 130: 3865-3876.

13. Plageman TF Jr, Yutzey KE. T-box genes and heart development: Putting the " $T$ " in heart. Dev Dyn 2005; 232: 11-20.

14. Bruneau BG, Nemer G, Schmitt JP, Charron F, Robitaille L, Caron $\mathrm{S}$, et al. A murine model of Holt-Oram syndrome defines roles of the T-box transcription factor Tbx 5 in cardiogenesis and disease. Cell 2001; 106: 709-721.

15. Brown DD, Martz SN, Binder O, Goetz SC, Price BM, Smith JC, et al. Tbx 5 and Tbx20 act synergistically to control vertebrate heart morphogenesis. Development 2005; 132: 553-563.

16. Moorman AF, Christoffels VM. Cardiac chamber formation: Development, genes, and evolution. Physiol Rev 2003; 83: 1223-1267.

17. Han Z, Yi P, Li X, Olson EN. Hand, an evolutionarily conserved bHLH transcription factor required for Drosophila cardiogenesis and hematopoiesis. Development 2006; 133: 1175-1182.

18. Angelo S, Lohr J, Lee KH, Ticho BS, Breitbart RE, Hill S, et al. Conservation of sequence and expression of Xenopus and zebrafish dHAND during cardiac, branchial arch and lateral mesoderm development. Mech Dev 2000; 95: 231 - 237.

19. Thomas T, Yamagishi H, Overbeek PA, Olson EN, Srivastava D. The bHLH factors, dHAND and eHAND, specify pulmonary and systemic cardiac ventricles independent of left-right sidedness. Dev Biol 1998; 196: 228-236.

20. Yamagishi H, Yamagishi C, Nakagawa O, Harvey RP, Olson EN, Srivastava D. The combinatorial activities of Nkx2.5 and dHAND are essential for cardiac ventricle formation. Dev Biol 2001; 239: 190-203.

21. Cai CL, Liang X, Shi Y, Chu PH, Pfaff SL, Chen J, et al. Isl1 identifies a cardiac progenitor population that proliferates prior to differentiation and contributes a majority of cells to the heart. Dev Cell 2003; 5: 877-889.

22. Lin L, Cui L, Zhou W, Dufort D, Zhang X, Cai CL, et al. Beta-catenin directly regulates Islet1 expression in cardiovascular progenitors and is required for multiple aspects of cardiogenesis. Proc Natl Acad Sci USA 2007; 104: 9313-9318.

23. Cohen ED, Wang Z, Lepore JJ, Lu MM, Taketo MM, Epstein DJ, et al. Wnt/beta-catenin signaling promotes expansion of Isl-1-positive cardiac progenitor cells through regulation of FGF signaling. J Clin Invest 2007; 117: 1794-1804.

24. Pandur P, Lasche M, Eisenberg LM, Kuhl M. Wnt-11 activation of a noncanonical Wnt signalling pathway is required for cardiogenesis. Nature 2002; 418: 636-641.

25. Tsuchihashi T, Maeda J, Shin CH, Ivey KN, Black BL, Olson EN, et al. Hand 2 function in second heart field progenitors is essential for 
cardiogenesis. Dev Biol 2011; 351: 62-69.

26. Dodou E, Verzi MP, Anderson JP, Xu SM, Black BL. Mef2c is a direct transcriptional target of ISL1 and GATA factors in the anterior heart field during mouse embryonic development. Development 2004; 131: 3931-3942.

27. von Both I, Silvestri C, Erdemir T, Lickert H, Walls JR, Henkelman RM, et al. Foxh1 is essential for development of the anterior heart field. Dev Cell 2004; 7: 331-345.

28. Yamagishi H, Srivastava D. Unraveling the genetic and developmental mysteries of 22q11 deletion syndrome. Trends Mol Med 2003; 9: 383-389.

29. Yamagishi H. The 22q11.2 deletion syndrome. Keio J Med 2002; 51: $77-88$.

30. Garg V, Yamagishi C, Hu T, Kathiriya IS, Yamagishi H, Srivastava D. Tbx1, a DiGeorge syndrome candidate gene, is regulated by sonic hedgehog during pharyngeal arch development. Dev Biol 2001; 235: $62-73$.

31. Xu H, Morishima M, Wylie JN, Schwartz RJ, Bruneau BG, Lindsay EA, et al. Tbx 1 has a dual role in the morphogenesis of the cardiac outflow tract. Development 2004; 131: 3217-3227.

32. Yamagishi H, Maeda J, Hu T, McAnally J, Conway SJ, Kume T, et al. Tbx1 is regulated by tissue-specific forkhead proteins through a common Sonic hedgehog-responsive enhancer. Genes Dev 2003; 17: $269-281$.

33. Maeda J, Yamagishi H, McAnally J, Yamagishi C, Srivastava D. Tbx1 is regulated by forkhead proteins in the secondary heart field. Dev Dyn 2006; 235: 701-710.

34. Hu T, Yamagishi H, Maeda J, McAnally J, Yamagishi C, Srivastava D. Tbx 1 regulates fibroblast growth factors in the anterior heart field through a reinforcing autoregulatory loop involving forkhead transcription factors. Development 2004; 131: 5491-5502.

35. Kume T, Jiang H, Topczewska JM, Hogan BL. The murine winged helix transcription factors, Foxc1 and Foxc2, are both required for cardiovascular development and somitogenesis. Genes Dev 2001; 15: $2470-2482$.

36. Seo S, Kume T. Forkhead transcription factors, Foxc1 and Foxc2, are required for the morphogenesis of the cardiac outflow tract. Dev Biol 2006; 296: 421-436.

37. Berridge MJ, Bootman MD, Roderick L. Calcium signaling: Dynamics, homeostasis and remodeling. Nat Rev Mol Cell Biol 2003; 4: $517-529$.

38. Uchida K, Aramaki M, Nakazawa M, Yamagishi C, Makino S, Fukuda $\mathrm{K}$, et al. Gene knock-outs of inositol 1,4,5-trisphosphate receptors types 1 and 2 result in perturbation of cardiogenesis. PLOS ONE 2010; 5: e12500.

39. Nakazawa M, Uchida K, Aramaki M, Kodo K, Yamagishi C, Takahashi T, et al. Inositol 1,4,5-trisphosphate receptors are essential for the development of the second heart field. J Mol Cell Cardiol 2011; 51: 58-66.

40. Aybar MJ, Mayor R. Early induction of neural crest cells: Lessons learned from frog, fish and chick. Curr Opin Genet Dev 2002; 12: $452-458$.

41. De Calisto J, Araya C, Marchant L, Riaz CF, Mayor R. Essential role of non-canonical Wnt signalling in neural crest migration. Development 2005; 132: 2587-2597.

42. Cheung M, Cheung M, Chaboissier MC, Mynett A, Hirst E, Schedl A, et al. The transcriptional control of trunk neural crest induction, survival, and delamination. Dev Cell 2005; 8: 179-192.

43. Meulemans D, Bronner-Fraser M. Gene-regulatory interactions in neural crest evolution and development. Dev Cell 2004; 7: 291-299.

44. Frank DU, Fotheringham LK, Brewer JA, Muglia LJ, Tristani-Firouzi M, Capecchi MR, et al. An Fgf8 mouse mutant phenocopies human 22q11 deletion syndrome. Development 2002; 129: 4591-4603.

45. Kubota Y, Ito K. Chemotactic migration of mesencephalic neural crest cells in the mouse. Dev Dyn 2000; 217: 170-179.

46. Vincent SD, Buckingham ME. How to make a heart: The origin and regulation of cardiac progenitor cells. Curr Top Dev Biol 2010; 90: $1-41$.

47. Toyofuku T, Yoshida J, Sugimoto T, Yamamoto M, Makino N, Takamatsu H, et al. Repulsive and attractive semaphorins cooperate to direct the navigation of cardiac neural crest cells. Dev Biol 2008; 321: $251-262$.

48. Kruger RP, Aurandt J, Guan KL. Semaphorins command cells to move. Nat Rev Mol Cell Biol 2005; 6: 789-800.

49. Brown CB, Feiner L, Lu MM, Li J, Ma X, Webber AL, et al. PlexinA2 and semaphorin signaling during cardiac neural crest development. Development 2001; 128: 3071-3080.

50. Feiner L, Webber AL, Brown CB, Lu MM, Jia L, Feinstein P, et al. Targeted disruption of semaphorin $3 \mathrm{C}$ leads to persistent truncus arteriosus and aortic arch interruption. Development 2001; 128: 3061-3070.

51. Chen S, Lechleider RJ. Transforming growth factor-beta-induced differentiation of smooth muscle from a neural crest stem cell line. Circ Res 2004; 94: 1195-1202.

52. Mignone JL, Kreutziger KL, Paige SL, Murry CE. Cardiogenesis from human embryonic stem cells. Circ J 2010; 74: 2517-2526.

53. Stottmann RW, Stottmann RW, Choi M, Mishina Y, Meyers EN, Klingensmith J. BMP receptor IA is required in mammalian neural crest cells for development of the cardiac outflow tract and ventricular myocardium. Development 2004; 131: 2205-2218.

54. Ross S, Hill CS. How the Smads regulate transcription. Int J Biochem Cell Bio 2008; 40: 383-408.

55. Jia Q, McDill BW, Li SZ, Deng C, Chang CP, Chen F. Smad signaling in the neural crest regulates cardiac outflow tract remodeling through cell autonomous and non-cell autonomous effects. Dev Biol 2007; 311: $172-184$.

56. Schott JJ, Benson DW, Basson CT, Pease W, Silberbach GM, Moak JP, et al. Congenital heart disease caused by mutations in the transcription factor NKX2-5. Science 1998; 281: 108-111.

57. Kodo K, Nishizawa T, Furutani M, Arai S, Yamamura E, Joo K, et al. GATA6 mutations cause human cardiac outflow tract defects by disrupting semaphoring-plexin signaling. Proc Natl Acad Sci USA 2009; 106: 13933-13938.

58. Maitra M, Koenig SN, Srivastava D, Garg V. Identification of GATA6 sequence variants in patients with congenital heart defects. Pediatr Res 2010; 68: 281-285.

59. Lin X, Huo Z, Liu X, Zhang Y, Li L, Zhao H, et al. A novel GATA6 mutation in patients with tetralogy of Fallot or atrial septal defect. J Hum Genet 2010; 55: 662-667.

60. Lepore JJ, Mericko PA, Cheng L, Lu MM, Morrisey EE, Parmacek MS. GATA-6 regulates semaphorin $3 \mathrm{C}$ and is required in cardiac neural crest for cardiovascular morphogenesis. J Clin Invest 2006; 116: $929-939$.

61. Rajagopal SK, Ma Q, Obler D, Shen J, Manichaikul A, TomitaMitchell A, et al. Spectrum of heart disease associated with murine and human GATA4 mutation. J Mol Cell Cardiol 2007; 43: 677685.

62. Xin M, Davis CA, Molkentin JD, Lien CL, Duncan SA, Richardson JA, et al. A threshold of GATA4 and GATA6 expression is required for cardiovascular development. Proc Natl Acad Sci USA 2006; 103: 11189-11194.

63. Kaichi S, Hasegawa K, Morimoto T. Excessive apoptosis as a downstream molecular event during the development of congenital heart diseases. Circ J 2010; 74: 2297-2298. 